\title{
KARAKTERISTIK WISATAWAN BACKPACKER DAN DAMPAKNYA TERHADAP PARIWISATA KUTA, BALI
}

\author{
Ni Nyoman Menuh \\ Email: c3m_2@yahoo.com
}

\begin{abstract}
The study investigates the characteristics of backpacker tourists in terms of socio demographic, socio-geographical, and sociopsychographic in Kuta, Bali. It also discusses the impacts of backpacker tourists to tourism development in terms of socioeconomic, socio-cultural and environmental aspects in the tourist destination of Kuta Bali. Combining the quantitative and qualitative approaches, this study used 272 respondents who represented the characteristics of foreign backpacker tourists, and respondents from the circle of businessmen, property managers, local communities and community leaders to determine the impacts of the presence of backpacker tourists to tourism industry in Kuta. The research findings shows that the characteristics of backpacker tourists are mostly young Europeans with professional jobs and have a high income. Backpacker tourists' arrivals not only bring the positive social, economic and cultural impacts but also negative environmental impacts. Some local people felt annoyance of the presence of backpacker tourists.
\end{abstract}

Keywords: backpacker tourists, tourist characteristics, tourist impacts, community response.

\section{Pendahuluan}

Kemajuan teknologi, perubahan struktur sosial dan berkembangnya dunia ekonomi telah menyebabkan peningkatan jumlah waktu yang tersedia untuk kegiatan bersantai dalam masyarakat modern. Bagi banyak orang berekreasi dengan banyak waktu memungkinkan mereka untuk mengejar hobi dengan melakukan perjalanan pariwisata yang telah menjadi pilihan yang populer (Chang, 2009: 712). Wisatawan mencari alternatif untuk mendapatkan apa yang dicita-citakan dan melakukan hal yang berbeda dari pariwisata massal. Backpacker merupakan salah satu dari sub-kelompok yang terlepas dari pariwisata massal dan berusaha untuk mencapai pengalaman pariwisata yang lebih lengkap (Currie et al., 2011:47). Menurunnya biaya transportasi dan pertumbuhan media komunikasi melalui internet membuat perjalanan wisata Backpacking ini terus meningkat (Maritha, 2010:1).

Karakteristik yang melekat pada wisatawan backpacker menyebabkan 


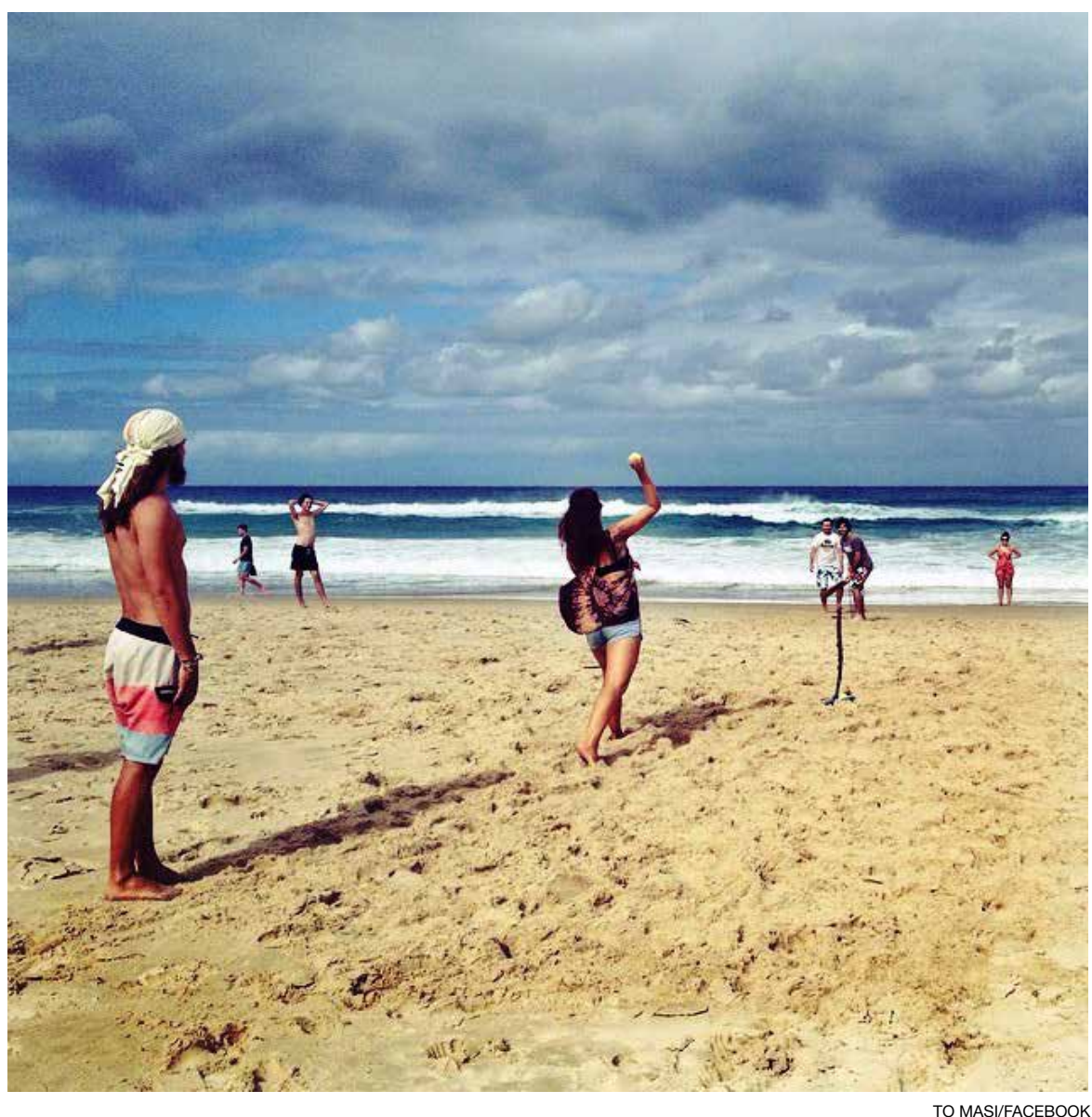

Foto 1. Wisatawan bermain di pantai Kuta, pantai yang terkenal sebabagi destinasi turis backpacker

dampak pembangunan yang luas terhadap ekonomi, sosial budaya dan lingkungan di daerah -daerah yang mereka kunjungi (Visser, 2004:283). Hampton (2014:106) telah mencatat bahwa wisatawan backpacker telah berdampak positif terhadap pembangunan ekonomi nasional di negaranegara seperti Thailand karena menawarkan kebocoran ekonomi kurang dari bentuk pariwisata lainnya (di mana kebocoran adalah proporsi uang yang harus dihabiskan untuk barang-barang yang harus diimpor).

Indonesia adalah salah satu negara yang menjadi destinasi wisata bagi para wisatawan backpacker. Acara Virgies Travel Guide yang ditayangkan di Metro TV menghadirkan lima kampung backpaker terbaik di Indonesia dalam segmen top five list salah satunya adalah Popies Lane (Kuta, Bali). Kuta sangat digemari oleh wisatawan backpacker. Ketersediaan akomodasi dan fasilitas wisata yang murah menyebabkan Kuta sebagai salah satu kantong wisatawan backpacker di Bali (Lihat Foto 1). 
Meskipun wisata ala backpacker sekarang ini sudah cukup berkembang, bahkan bergeser menjadi flashpacker (tampil lebih mewah dengan gadget dan lifestyle baru), tetapi pada kenyataannya wisata ala backpacker masih belum dijadikan prioritas dalam perencanaan pariwisata, terutama di negara-negara Asia Tenggara (Tze and Musa, 2005) termasuk Indonesia. Hal ini dikarenakan karakteristik backpacking selalu ditunjukan sebagai bentuk wisata yang sering dianggap Grand Tour dari kelas bawah, seperti membawa ransel, berkemah dan menekankan dengan wisata yang mempunyai anggaran yang rendah (Gula, 2006:3). Backpacker sering dianggap tidak berdampak signifikan terhadap perekonomian (Wallstam, 2011:5).

Pengenalan karakteristik wisatawan dapat memberikan gambaran pola permintaan wisatawan ini di masa kini dan di masa yang akan datang yang tentunya akan berdampak bagi pengembangan pariwisata dilihat dari segi sosial ekonomi, sosial budaya, dan lingkungan sehingga diperlukan penelitian yang lebih lanjut mengenai keberadaan backpacker di Bali.

Dua hal yang dibahas dalam artikel ini adalah bagaimanakah karakteristik backpacker mancanegara dilihat dari sosio demografis, sosio geografis dan sosis psikografis yang ada di kawasan pariwisata Kuta Bali?; bagaimana dampak yang ditimbulkan wisatawan backpacker mancanegara terhadap pengembangan pariwisata dari segi sosio ekonomis, sosial budaya dan lingkungan di kawasan pariwisata Kuta Bali?

\section{Karakteristik Wisatawan}

Secara etimologis, istilah karakteristik diambil dari bahasa Inggris yaitu characteristic, artinya sifat-sifat yang khas dari sesuatu. Chaplin (dalam blog. uin-malang.ac.id) menjelaskan bahwa karakteristik merupakan sinonim dari kata 'karakter, watak, dan sifat'. Tourist descriptor memfokuskan pada wisatawannya, biasanya digambarkan dengan Who wants what, why, when, where and how much?" Untuk menjelaskan hal-hal tersebut digunakan beberapa karakteristik di antaranya karakteristik sosio demografis, karakteristik geografis, dan karakteristik psikografis.

Karakteristik sosio-demografis mencoba menjawab pertanyaan "who wants what". Pembagian berdasarkan karakteristik ini paling sering dilakukan untuk kepentingan analisis pariwisata, perencanaan dan pemasaran, karena sangat jelas definisinya dan relative mudah pembagiannya (Kottler 1996:129). Yang termasuk dalam karakteristik sosio demografis diantaranya adalah jenis kelamin, umur, status perkawisan, tingkat pendidikan, pekerjaan, kelas sosial, ukuran keluarga atau jumlah anggota keluarga dan lain-lain yang dielaborasi dari karakter tersebut.

Karakteristik geografis membagi wisatwan berdasarkan lokasi tempat tinggalnya, biasanya dibedakan menjadi desa-kota, provinsi maupun negara asalnya. Pada tulisan ini hanya ditelusuri asal negara wisatawan. 
Karakteristik ini membagi wisatawan ke dalam kelompok-kelompok berdasarkan kelas sosial, life style dan karakteristik personal. Wisatawan dalam kelompok demografis yang sama mungkin memiliki profil psikografis yang sangat berbeda (Smith, 1977:81)

\section{Teori dan Metode}

Masalah dalam artikel ini dianalisis dengan dua teori yaitu dampak pariwisata dan teori indeks iritasi dari Doxey. Kedua teori ini saling menunjang karena salah satu cara untuk mengukur dampak adalah indeks gangguan atau iritasi yang dirasakan masyarakat.

Industri pariwisata adalah kegiatan yang sangat kompleks dan sensitif menimbulkan berbagai dampak, positif atau negatif atau keduanya. Para sarjana menggolongkan berbagai jenis dampak yang diakibatkan oleh perkembangan pariwisata. Pitana (2009:184) menggolongkan menjadi tiga yaitu dampak ekonomi, dampak sosial, dan dampak lingkungan. Adapun penjelasannya adalah sebagai berikut.

Dampak ekonomi pariwisata muncul karena wisatawan yang berkunjung ke suatu destinasi adalah seorang konsumen. Mereka datang ke daerah tersebut dalam jangka waktu tertentu, menggunakan sumber daya dan fasilitasnya dan biasanya mengeluarkan uang untuk berbagai keperluan, dan kemudian meninggalkan tempat tersebut untuk kembali ke rumah atau negaranya.

Dampak sosial budaya terjadi karena pertemuan antara social budaya lokal dengan kebutuhan industri pariwisata. Dampak pariwisata terhadap kehidupan sosial budaya didokumentasikan dengan sangat baik oleh Smith (1977:59) yang pada intinya ingin menjawab tiga pertanyaan pokok, yaitu: (1) bagaimana karakteristik interaksi antara wisatawan dengan masyarakat lokal (host-guest); (2) bagaimana proses pariwisata dapat mengubah masyarakat dan budaya masyarakat tuan rumah, dan; (3) apakah perubahan tersebut menguntungkan atau merugikan bagi tuan rumah. Ahli lain yang menaruh perhatian mengenai dampak pariwisata terhadap sosial budaya adalah Butcher (2003:55), yang menyoroti interaksi pariwisata dengan masyarakat lokal, khususnya dan sisi perubahan moral. Hal ini diduga karena sifat wisatawan yang 'terlalu bebas' dalam berperilaku di daerah tujuan wisata.

Sama halnya perubahan social budaya, perkembangan industri pariwisata juga menimbulkan dampak lingkungan fisik. Pentingnya lingkungan alam untuk mendukung suatu kawasan menjadi daerah tujuan atau objek wisata tidak terbantahkan lagi. Meskipun bukan faktor utama atau satu-satunya yang menarik wisatawan untuk berkunjung, tetapi faktor lingkungan dan alam mempunyai pengaruh signifikan bagi calon wisatawan mengapa memilih daerah tersebut sebagai daerah tujuan wisata. Di sisi lain, tidak dapat 
dipungkiri juga aktivitas pariwisata di suatu kawasan akan menimbulkan dampak terhadap alam dalam derajat tertentu. Hal inilah yang menjadi perhatian besar agar pembangunan pariwisata tidak berdampak negatif bagi lingkungan dan alam.

Salah satu cara mengukur dampak pariwisata dapat diamati dengan irritation index (irridex) yang dikembangkan oleh Doxey (Richardson dan Fluker, 2004:135-136). Irridex merupakan indeks yang dapat dipakai untuk mengukur kecenderungan respon masyarakat terhadap perkembangan pariwisata. Tahapan tersebut adalah sebagai berikut.

Euphoria (Perasaan bangga rohani dan Jasmani). Masyarakat lokal mendukung pembangunan pariwisata dan mereka siap hidup berdampingan dalam kehidupan sehari-hari dengan wisatawan. Umumnya masyarakat mengharapkan dan memperkirakan akan mendapatkan keuntungan dan pekerjaan baru yang akan didapat, peningkatan pendapatan, dan peningkatan nilai ekonomi property yang mereka miliki.

Apathy (Sikap acuh tak acuh). Akhirnya pertumbuhan industri pariwisata mulai mengalami penurunan. Pariwisata yang telah diterima sebagai sektor yang memacu pertumbuhan ekonomi kawasan tidak lagi dianggap segala-galanya. Struktur sosial kawasan mulai mengalami perubahan oleh kedatangan orang baru yang mencari pekerjaan, peranan keluarga mengalami perubahan karena anggota keluarganya bekerja di pariwisata.

Annoyance (sikap terganggu/ terusik). Jika tahapan pengembangan pariwisata terus berlanjut, tahapan iritasi sosial mungkin terjadi. Saat ini perkembangan pariwisata mulai tidak lagi sesuai perencanaan awal dan mulai meluas ke area yang sensitif terhadap perubahan lingkungan. Masyarakat lokal harus mulai berbagi tempat rekreasi yang sebelumnya mereka miliki. Harga makanan naik lebih cepat daripada kenaikan pendapatan. Kerusakan lingkungan yang menyebabkan objek wisata tidak lagi menarik sehingga kunjungan wisatawan menurun.

Antagonism/ Xenophobia (rasa benci/ pertentangan). Sejalan dengan semakin meningkatnya perasaan kehilangan 'tempat' yang secara tradisional dipergunakan oleh masyarakat lokal, masyarakat menyalahkan wisatawan atas perubahan ini dibandingkan dengan pembangunan pariwisata yang tidak terencana dan tidak terkontrol dengan baik. Ada kecenderungan wisatawan yang datang selama masa euphoria telah digantikan oleh tipe wisatawan baru yang kurang menghargai kearifan lokal tetapi terfokus pada ketertarikan faktor fisik alam.

Metode analisis data yang digunakan dalam penelitian ini adalah deskriptif kuantitatif dan deskriptif kualitatif. Sampel dalam penelitian ini berjumlah 272 orang responden Backpacker untuk meneliti mengenai karakteristik backpacker serta responden yang terdiri dari tokoh masyarakat, pengelola akomodasi murah, pelaku usaha dan masyarakat lokal untuk mengetahui 
dampak yang ditimbulkan oleh kedatangan backpacker. Lokasi penelitian dilakukan di akomodasi yang sering dikunjungi oleh wisatawan backpacker di kawasan wisata Kuta seperti Hostel Kayun, Mahendra Beach Inn, Gemini Star Hotel, Ronta Bungalows dan Losmen Arthawan.

\section{Karakteristik Wisatawan Backpacker Mancanegara}

Hasil penelitian menujukan bahwa wisatawan backpacker berasal dari berbagai negara. Wisatawan backpacker didominasi oleh wisatawan yang berasal dari benua Eropa yaitu sebesar 59 persen yang terdiri dari negara Perancis, Jerman, Scotlandia, Inggris, Swedia, Denmark, Finlandia, Belanda, dan Slovenia serta negara dari Eropa lainnya. Ketertarikan bangsa Eropa untuk melakukan perjalanan dengan cara backpacking sangat tinggi, hal ini didukung oleh kecintaan bangsa Eropa terhadap hal-hal yang berhubungan dengan budaya, bangsa Eropa juga sangat menghargai budaya lokal (TFS, 2011:48).

Selain Eropa, wisatawan yang berasal dari benua Australia yaitu sebesar 19 persen juga memiliki ketertarikan yang cukup tinggi dalam melakukan perjalanan dengan cara backpacking ke Bali. Letak Australia yang dekat dengan Indonesia khususnya Bali mendukung keberadaan backpacker Australia di Bali. Wisatawan yang berasal dari Amerika (18 persen) dan Asia (4 persen) juga memilih gaya backpacking dalam menikmati perjalanan wisatanya.

Karakteristik sosio demografis dibagi berdasarkan usia, jenis kelamin, usia, jenis kelamin, tingkat pendidikan, pekerjaan dan tingkat pendapatan. Berdasarkan usia, wisatawan backpacker didominasi oleh backpacker yang berusia muda. Backpackers pada umumnya berasal dari kalangan muda yang memiliki jiwa petualang dan rasa ingin tahu yang tinggi serta tidak ingin terikat dengan paket wisata tertentu yang mengekang kebebasan backpackers.

Berdasarkan jenis kelamin, menunjukan wisatawan backpacker yang berkunjung ke kawasan pariwisata Kuta didominasi oleh kaum perempuan Jumlah wisatawan backpacker perempuan tinggi berarti perempuan memiliki minat yang tinggi dalam berwisata dengan gaya backpacker.

Dilihat dari sudut pandang pendidikan, backpacker yang berkunjung ke kawasan pariwisata Kuta merupakan kaum terpelajar dan memiliki pendidikan. Keinginan para backpacker untuk melakukan wisata dengan cara backpacking didasarkan pada pengetahuan mengenai suatu daerah yang diperoleh dari sumber informasi yang dipercaya sehingga memunculkan keinginan untuk menjelajahi dengan cara yang berbeda dari jenis wisatawan pada umumnya (menggunakan paket wisata). Tingkat pendidikan yang tinggi mendorong mereka untuk lebih cerdas memilih tempat wisata yang sesuai dengan keinginan para backpackers tersebut. 
Karakteristik wisatawan backpacker berdasarkan pekerjaan menunjukan bahwa backpacker mempunyai pekerjaan yang bervariasi dari pekerja tetap hingga pekerja freelance. Jenis pekerjaan wisatawan sebagai freelance mendominasi jenis pekerjaan yang dimilik oleh wisatawan backpacker. Hal ini berarti peminat berwisata dengan cara backpacker tidak hanya wisatawan yang mempunyai pekerjaan dengan waktu yang sangat luang tetapi juga diminati oeh wisatawan yang mempunyai keterikatan waktu dengan pekerjaan. Berwisata dengan cara backpacking akan memberikan keluasaan bagi backpacker untuk dapat memanfaatkan waktu dengan sebaik-baiknya agar mendapatkan kesenangan yang diinginkannya karena backpacker tidak terikat dengan jadwal wisata yang ditawarkan oleh agenagen biro perjalanan.

Karakteristik psikografis wisatawan backpackers yang berkunjung ke Bali dapat dilihat dari beberapa dimensi seperti teman perjalanan, jumlah kunjungan, transportasi, objek wisata yang dikunjungi, lama tinggal, akomodasi, destinasi yang dikunjungi selain Bali, pemilihan tempat makan, cara mengetahui Bali, aktivitas wisata, anggaran berwisata serta pola pengeluaran.

Destinasi yang dikunjungi oleh wisatawan backpacker selain Bali adalah destinasi di Indonesia seperti Gili Trawangan yang berada di Nusa Tenggara Barat (Lombok), NTT, Jawa, Labuan Bajo, Sumatera, Kalimantan Sulawesi dan Jakarta. Wisatawan backpacker juga mengunjungi Asia seperti India, Thailand, Singapore, Malaysia, Kamboja, dan Vietnam. Serta wisatawan yang mengunjungi tempat lainnya seperti Jepang, Korea Selatan, Afrika dan Amerika.

Wisatawan backpacker dominan berencana ingin mengunjungi obyek wisata di Bali Timur yang berada di Kabupaten Gianyar (Sukawati, Gianyar, Ubud, Tampaksiring), Kabupaten Karangasem (Padangbai, Tulamben dan Gunung Agung) dan Kabupaten Klungkung (Nusa Penida).

Berdasarkan karakteristik wisatawan backpacker berdasarkan lama kunjungan di Bali menunjukan bahwa sebagian besar lama berkunjung di Bali selama 8-15 hari. Wisatawan backpacker yang berkunjung ke kawasan wisata Kuta lebih banyak memilih menggunakan sepeda motor. Hostel/ Losmen menjadi akomodasi favorit bagi para backpacker dikarenakan harganya yang murah. Pemilihan hostel/ mostel/ guesthouse/ losmen juga disebabkan oleh keinginan backpacker untuk dapat berinteraksi dengan masyarakat lokal dan berbagi informasi dengan sesama backpacker. Wisatawan backpacker lebih banyak makan di restoran lokal. Backpacker sebagian besar suka makan di restoran lokal karena backpacker mempunyai keinginan untuk merasakan makanan lokal yang dimasak oleh orang lokal sehingga backpacker dapat mendalami perannya dalam kehidupan masyarakat setempat. 


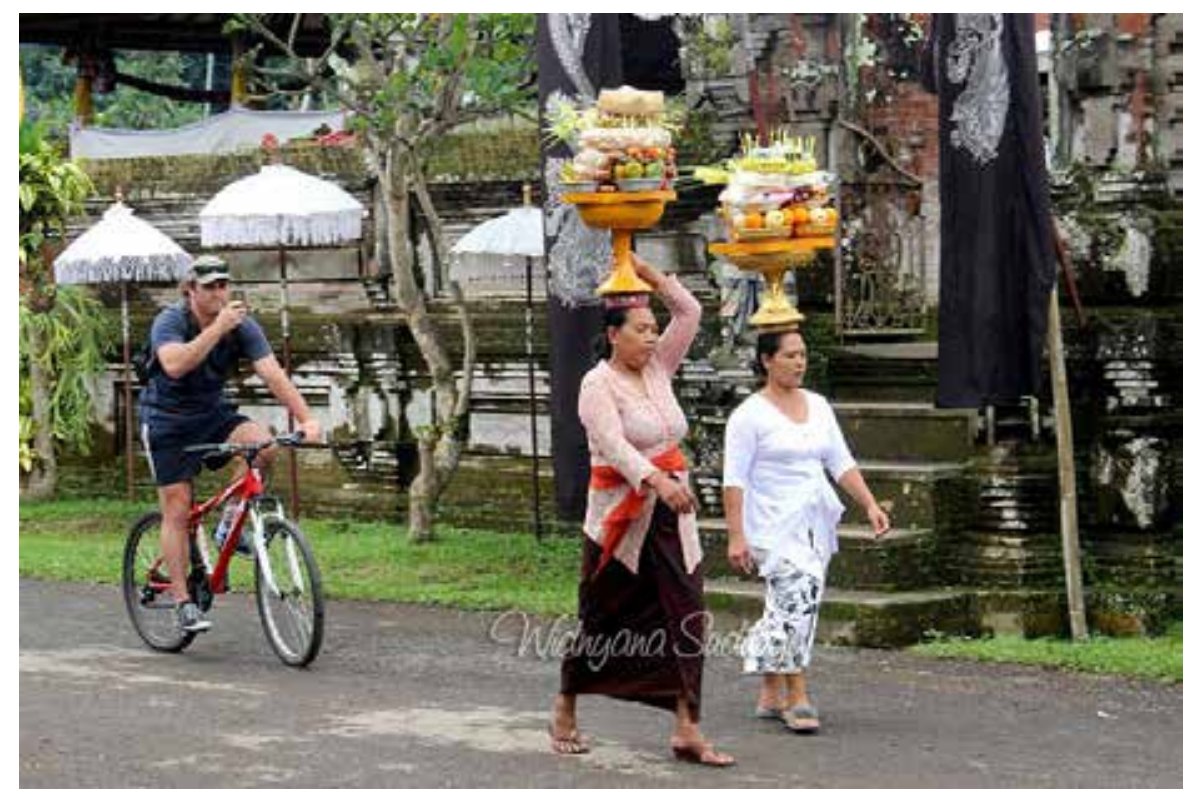

WIDNYANA SUDIBIA

Foto 2. Wisatawan backpacker naik sepeda menelusuri pedesaan Bali.

Backpacker kebanyakan baru pertama kali mengunjungi Bali sehingga backpacker lebih sering mengajak teman sebagai teman seperjalanan dibandingkan sendiri atau mengajak keluarga. Referensi teman merupakan sumber informasi yang paling banyak digunakan oleh wisatawan backpacker untuk mengunjungi suatu daerah yang belum dikenalinya. Backpacker mempunyai banyak aktivitas favorit selama berkunjung ke Bali seperti snorkeling, diving, surfing, hiking biking (Lihat Foto 2).

Berdasarkan penelitian di lapangan, rata-rata pengeluaran wisatawan backpacker selama berlibur di Kuta dengan rata-rata lama tinggal adalah 8 hari sebesar Rp. 7.840.202,00 dengan rata-rata pengeluaran per hari sebesar Rp.938.156,oo. Besaran rata-rata pengeluaran wisatawan backpacker mancanegara untuk akomodasi adalah sebesar Rp. 142.737 per hari per orang. Rata-rata pengeluaran dihabiskan untuk untuk transportasi adalah sebesar Rp. 934.559 per orang.

Rata-rata pengeluaran dihabiskan untuk makan dan minum adalah sebesar Rp 64.283 per makan per orang. Rata-rata pendapatan wisatawan backpacker per tahunnya adalah sebesar USD \$ 35.243 per tahun atau sebesar Rp. 458.163.971,oo (dengan asumsi $1 \$=$ Rp. 13.0oo) maka sebesar 2,22 persen biaya yang mereka keluarkan dari total pendapatan yang wisatawan backpacker diperoleh setiap tahunnya untuk berwisata ke Bali.

\section{Dampak Kunjungan Wisatawan Backpacker}

Kedatangan wisatawan backpacker secara tidak langsung membuka 
peluang dalam menciptakan lapangan kerja di sektor pariwisata seperti restoran, akomodasi murah dan sebagai pemandu wisata pribadi. Peningkatan pendapatan secara signifikan pada pelaku wisata (warung makan, jasa sewa motor dan toko cinderamata ) dan masyarakat lokal sejak wisatawan backpacker berbelanja ke tempat usahanya. Terdapat perubahan mata pencaharian masyarakat ke sektor pariwisata yang lebih menjanjikan seperti sektor pertanian ke pengelola akomodasi murah, dari supir menjadi penyewa sepeda motor, dari buruh ke penjual aksesoris.

Backpacker melakukan interaksi dengan masyarakat lokal dalam bentuk komunikasi verbal dengan masyarakat lokal saat menyaksikan proses upacara agama. Wisatawan backpacker sangat tertarik dengan nilai-nilai adat yang ada di dalam masyarakat. Interaksi yang terjadi antara backpacker dengan masyarakat menimbulkan perubahan terhadap gaya hidup masyarakat seperti perubahan terhadap paradigm masyarakat tentang kehidupan dan semangat hidup. Pertukaran bahasa dan perubahan gaya hidup kearah modern sering terjadi diantara masyarakat lokal.

Dampak kedatangan backpacker tidak selalu dirasakan positif oleh masayrakat. Terkadang ada peniruan tingkah laku oleh penduduk lokal yang dirasa tidak cocok dengan budaya lokal seperti perubahan tingkah laku yang senang ke pub, minum minuman beralkohol dan memakai tattoo. Gaya hidup sebagaian kecil masyarakat lokal juga berubah menjadi lebih konsumtif. Backpacker yang melakukan perjalanan tanpa pemandu wisata juga rawan melalukan tindak pelanggaran seperti masuk ke areal suci tanpa mengenakan pakaian adat atau dalam keadaan menstruasi.

Secara tidak langsung backpacker pun membawa dampak yang kurang baik bagi lingkungan. Permintaan terhadap akomodasi murah yang terus meningkat menyebabkan pembangunan hostel ataupun hotel kecil semakin tidak terkontrol sehingga lahan hijau semakin terdesak. Terkadang masyarakat juga membuka akomodasi murah tanpa memenuhi izin yang berlaku.

\section{Respon Masyarakat terhadap Wisatawan Backpacker}

Sesuai dengan hasil wawancara, responden sangat mengharapkan kedatangan wisatawan backpacker karena wisatawan backpacker memberikan dampak yang positif terhadap perkembangan masyarakat. Namun dibalik itu terdapat juga dampak negatif yang dirasakan oleh masyarakat terkait dengan kedatangan backpacker ke wilayah Kawasan Pariwisata Kuta. Dampak tersebut terjadi peniruan tingkah laku dan gaya hidup backpacker yang tidak cocok dengan budaya lokal.

Masyarakat juga menilai bahwa backpacker yang tidak menggunakan jasa pemandu wisata cenderung dapat melanggar aturan. Hal ini berarti respon masyarakat Kawasan Wisata Kuta terhadap kedatangan backpacker 
berada pada tahap annoyance. Walaupun masyarakat lokal memperoleh pendapatan dari datangnya wisatawan backpacker tetapi pendapatannya masih tergolong lebih kecil dibandingkan dengan para pendatang yang mempunyai modal yang lebih besar. Banyaknya jumlah akomodasi murah yang ditawarkan untuk backpacker menimbulkan persaingan yang semakin tajam. Kadang tidak memberikan pendapatan yang berarti bagi pemilik akomodasi saat musim tamu sepi.

Terjadi peniruan masyarakat lokal terhadap tingkah laku dan gaya hidup backpacker yang tidak sesuai dengan budaya lokal sehingga dapat memberikan efek negative terhadap nilai-nilai luhur dalam masyarakat apabila dibiarkan dan terjadi terus menerus di dalam masyarakat tanpa adanya perlindungan kuat terhadap budaya lokal.

\section{Simpulan dan Saran}

Berdasarkan hasil penelitian maka simpulan dari hasil penelitian ini adalah wisatawan backpacker dominan berasal dari benua Eropa yang mempunyai usia muda dengan pekerjaan yang mempunyai waktu yang senggang yang mayoritas adalah kaum perempuan. Sebagaian backpacker mempunayai pendapatan yang cukup tinggi. Wisatawan Backpacker sebagain besar berencana untuk mengunjungi obyek wisata di kawasan Bali Timur. Wisatawan backpacker cenderung menghabiskan waktu yang lama di Bali berkisar 8-15 hari.

Untuk dapat mendapatkan keinginnanya wisatawan backpacker sangat perhitungan dalam mengeluarkan anggaran sehingga lebih sering menginap di akomodasi yang murah seperti hostel dan makan di warung atau rumah makan lokal. Kebanyakan backpacker yang datang ke Kuta merupakan wisatawan backpacker yang baru pertama kali ke Bali sehingga sering mengajak teman sebagai teman seperjalanan. Informasi mengenai destinasi wisata pun kebanyakan diterima dari teman yang dipercaya. Backpacker sangat menyenangi wisata alam seperti diving dan surfing.

Dampak yang ditimbulkan oleh wisatawan backpacker dapat berdampak positif dan negative. Dampak positif yang ditimbulkan seperti dalam peningkatan pendapatan masyarakat karena banyak yang beralih mata pencaharian dari sektor non pariwiwsata ke sektor pariwisata. Perubahan pola pikir yang menjadi lebih modern dan terbuka pun dirasakan oleh masyarakat lokal. Wisatawan backpacker sangat ingin mempelajari nilainilai tradisi masyarakat lokal dengan mengikuti proses upacara agama atau adat. Akan tetapi masyarakat juga merasakan dampak negatif yang ditimbulkan seperti terpengaruhnya masyarakat terhadap perubahan gaya hidup dan tingkah laku backpacker yang tidak sesuai dengan budaya lokal. serta secara tidak langsung mempengaruhi perubahan lingkungan seperti perkembangan akomodasi yang semakin menjamur. 
Saran yang diberikan untuk dapat mempertahankan dan mengembangan pariwiwsata di kawasan wisata Kuta adalah dengan penaatan kembali cara mendisiplinkan wisatawan-wisatawan asing yang datang ke wilayah kawasan pariwisata Kuta untuk menjaga ketertiban dan keharmonisan antara wisatawan dengan masyarakat lokal. Pemerintah wilayah Kuta melakukan penertiban terhadap perijinan akomodasi murah. Pemerintah wilayah Kuta diharapkan melaksanakan imbauan mengenai moratorium pembangunan hotel di Bali Selatan sesuai dengan Surat Gubernur Bali No. 570/1665/ BPM tentang Penghentian Sementara Pendaftaran Penanaman Modal Untuk Bidang Usaha Jasa Akomodasi Pariwisata, saran untuk penelitian selanjutnya adalah penelitian penelitian untuk karakteristik wisatawan backpacker dapat dilakukan secara kuantitatif maupun kualitatif sehingga dapat mengetahui motivasi wisatawan backpacker datang ke Bali.

\section{Ucapan Terimakasih}

Penulis menyampaikan ucapan terimakasih kepada seluruh pihak yang memberikan masukan, isnspirasi dan bantuan dalam penyusunan artikel ini. Ucapan terimakasih penulis ucapkan kepada Dr. Ir. Syamsul Alam Paturusi, MSP dan Dr. Ir. I Made Adhika, MSP sebagai pembimbing yang selalu memberikan masukan sampai artikel ini selesai. Serta rekanrekan seangkatan yang telah ikut berpartisipasi memberikan saran dalam penyempurnaan artikel ini.

\section{Daftar Pustaka}

Chang, Shan-Ju L. 2009. Information Research in Leisure: Implications from an Empirical Study of Backpackers. Library Trens/ Spring. 57 (4), pp: 711-728.

Currie, Russel R, Tamara Campbell-Trant and Sheilag Seaton. 2011. Joining The In-Crowd: Symbol For Backpacker Identity. International Journal of Culture Tourism and Hospitality Reaserch. 5 (1), pp: 47-56.

Gula, Lauren. 2006. Backpacking Tourism: Morally Sound Travel or Neo-Colonial Conquest?. Thesis. International Development Studies, Dalhousie University.

Hampton, Mark P. 2014. Backpacker Tourism and Economic Development: Perspectives from the less Developed World. Progress in Development Studies. 14(1), pp: 105-114.

Kottler, Phiplip. 1990. Manajemen Pemasaran: Analsis, Perencanaan, Implementasi, dan Pengendalian. Jilid II. Edisi Kelima. Jakarta: Erlangga.

Maritha, Devi Putri. 2010. Profil Pola Pengeluaran Wisatawan Asing Ala "Backpacker" di Yogyakarta. Universitas Sebelas Maret Surakarta.

Pitana, I.G dan Gayatri. 2005. Sosiologi Pariwisata. Yogyakarta: Andi

Richarson, John and Martin Fluker. 2004. Understanding and Managing Tourism. Australia: Person Education Australia, NWS Australia.

Smith, Shaun \& Wheeler, Joe. 2002. Managing The Custumer Experience. New 
York: Prentice Hall.

Tim Peneliti Mahasiswa PS. Manajemen Kepariwisataan 2008 STP. 2013. Karakteristik Wisatawan Backpakers Mancanegara dan Dampaknya Terhadap Ekonomi dan Sosial Budaya. Jurnal Kepariwisataan. 12(2), pp: 176-183

Tze Ian, Lee and Musa. 2005. Uncovering International Backpacker to Malaysia. Backpacker Tourism. 2(1), pp: 139-143

Visser, Gustav. 2004. The Development Impact of Backpacker Tourism in South Africa. GeoJournal. 60 (3), pp: 283-299.

Wallstam, Martin. 2011. Backpacker Institionalization. Thesis. Mittuniversitetet. Mid Sweden University.

\section{Profil Penulis}

Ni Nyoman Menuh adalah mahasiswa Magister Kajian Pariwisata angkatan Tahun 2013. Ia menyelesaikan Program studi Sarjana Strata I di Fakultas Ekonomi Universitas Udayana. Sampai saat ini masih menjadi tenaga pengajar mata kulian Manajemen di Sekolah Tinggi Ilmu Manajemen Indonesia (STIMI) Handayani Denpasar. 